\title{
INSTRUMENTATION AND MONITORING OF A CONCRETE JACKING PIPE
}

\author{
B.M. Phillips ${ }^{1,2 *}$, R. Royston ${ }^{1,2}$, B.B. Sheil ${ }^{1}$, B.W. Byrne ${ }^{1}$ \\ ${ }^{1}$ Department of Engineering Science, University of Oxford, Oxford, U.K. \\ ${ }^{2}$ Ward and Burke Construction Ltd, Kilcolgan, Galway, Ireland
}

\begin{abstract}
Microtunnelling, specifically pipe-jacking, is an increasingly popular non-disruptive means of constructing underground conduits for water, sewage, and other utilities. The construction process involves jacking a pipe string through the ground while controlled excavation is undertaken at the face. The drive lengths that can be achieved using this form of construction are largely a function of the frictional forces that develop at the pipe-soil interface during jacking. However, design methods currently used in industry can provide poor predictions of the forces generated during pipe-jacking. This paper describes the development of a full-scale instrumented concrete pipe to inform the development of an improved basis for design. The pipe section is instrumented to measure the (a) normal and bi-directional shear contact stresses, (b) lubricant pressure, and (c) wall strains (hoop, axial, $45^{\circ}$ ) around the pipe circumference. The instrumented pipe section was trialled on a recent pilot project in the UK involving the construction of a $2.2 \mathrm{~m}$ internal diameter microtunnel in mudstone. Now complete, the microtunnel measures over $1.2 \mathrm{~km}$ length making it the longest drive of its kind to be completed in the UK.
\end{abstract}

\section{Notation}

$\mu \quad$ Friction factor

$A_{\mathrm{p}} \quad$ Pipe joint packer area

$E \quad$ Elastic modulus

$F \quad$ Total skin friction force

$f$ Allowable maximum stress

$F_{\mathrm{ck}} \quad$ Concrete compressive strength

$P \quad$ Total jacking force

$R$ Total face resistance

$\gamma \quad$ Safety factor

$\varepsilon \quad$ Strain

\section{Introduction}

Microtunnelling provides an alternative to traditional open cut methods of pipe installation. It is particularly suited to urban environments where disruption at ground level is confined to the launch and reception shafts rather than along the full pipe length. It also provides a means of installing pipelines beneath impassable obstructions such as railway lines, major roads, rivers, and topographical features.

One of the key criteria for the selection of pipe-jacking as a preferred method of construction is the cost of the drives. Historically, tunnels constructed using pipe-jacking are straight, short in length $(<200 \mathrm{~m})$ and have a constant vertical incline. Recent advances in guidance systems and tunnelling equipment means that longer tunnels, often with curves, are now routinely constructed using pipe-jacking. The ability to construct longer and curved drives improves the economy of the construction process by reducing the number of shafts to receive and launch the tunnel boring machines (TBMs).
The total force, $P$, required to jack a pipe string is composed of the TBM face resistance, $R$, and the frictional force acting on the exterior surface of the pipe string, $F$ (Pellet-Beaucour and Kastner, 2002). The force $P$ is limited to the available thrust that can be applied to the string, which relies on the capacity of the jacking frame, thrust wall, and jacking pipes being used. The limits of the available thrust determine the maximum length of drive that can be completed before inter-jack stations are required. For long drives, the total jacking force required to construct the tunnel is dominated by the frictional force. Quantifying the frictional resistance between the pipe string and surrounding soil over the duration of the drive is essential to predict jacking forces. Currently no unified theory exists for the calculation of pipe friction.

Research is underway at University of Oxford to provide an improved basis for the calculation of skin friction and pipe forces during pipe-jacking. This paper discusses the development of an instrumented test pipe to monitor (a) pipe strains, (b) local shear and normal contact stresses, and (c) porewater pressures during pipe-jacking. The instrumented pipe was trialled on a recent UK pilot project in Cumbria, U.K. Exemplar data obtained from the instrumented pipe during the drive are also presented.

\section{Overview of pipe jacking process}

This paper focuses on slurry TBMs which use a (typically bentonite) slurry to transport material from the cutting face to the surface. A separation plant is located in close proximity to the launch shaft to clean the slurry waters. Removing the 
excavated material from the slurry is a multi-stage process involving screens of various passing sizes, hydro-cyclones, clay ballers, and centrifuges (Liu, 2010).

The construction of a pipe-jacked drive begins from the launch shaft, as shown in Figure 1. The jacking frame and guide rails are installed between a 'headwall' and a heavily-reinforced 'thrust wall'. To advance the drive, controlled excavation is conducted at the face of the TBM whilst the jacking frame applies an axial load to the pipe string. The TBM excavation diameter is slightly greater than that of the pipes to produce an annulus that encapsulates the pipe string. This is intended to reduce the development of frictional forces.

\section{Figure 1. Schematic of the pipe-jacking construction} process (image courtesy of Herrenknecht)

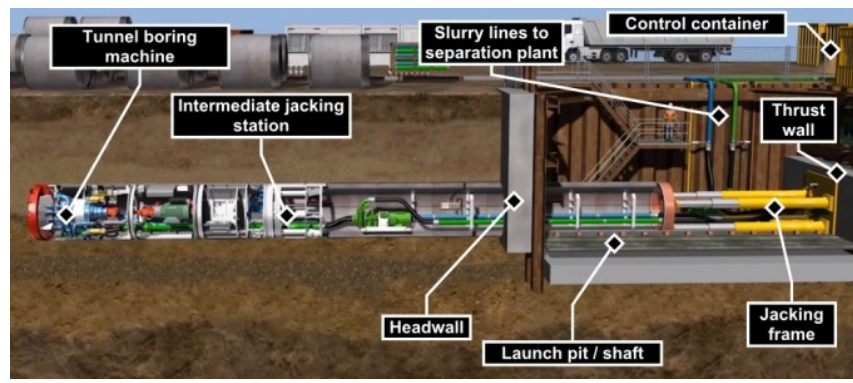

Additional 'intermediate jacking stations' (IJS; see Figure 2) are often installed at regular intervals within the pipe string if it is expected that the axial force required to advance the string may exceed the capacity of: (a) the thrust wall, (b) the jacking frame, or (c) the jacking pipes. A key challenge associated with the use of IJS is that the tunnel designer needs to estimate in advance of tunnel construction how many stations within the drive could be required.

Figure 2. Intermediate jacking station for a $2286 \mathrm{~mm}$ / $2756 \mathrm{~mm}$ inside / outside diameter pipe

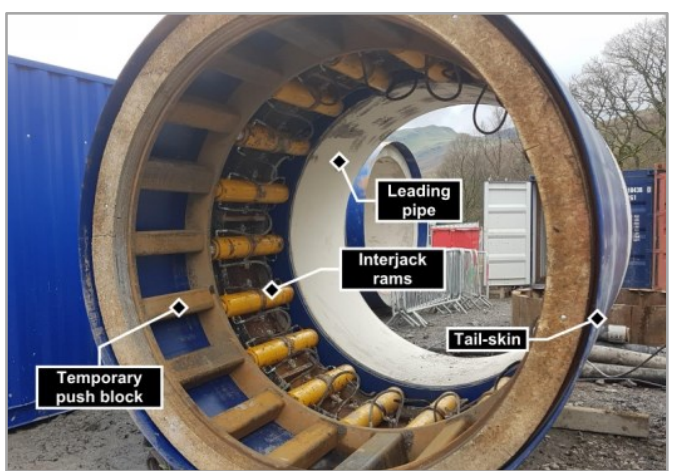

Once a pipe has been jacked into the string (i.e. the jacking rams are fully-extended), the rams are retracted, and a new pipe is lowered into position on the guide rails (see Figure 3). This process is then repeated for each additional pipe to be inserted into the string. The drive terminates when the TBM excavates through the wall of the reception shaft where a reception seal provides protection against water ingress. The TBM is then extracted from the shaft and all services are stripped from the inside of the tunnel for reuse. Finally, the tunnel is thoroughly cleaned prior to commissioning.

Figure 3. Photo showing jacking frame rams retracting prior to insertion of a new pipe

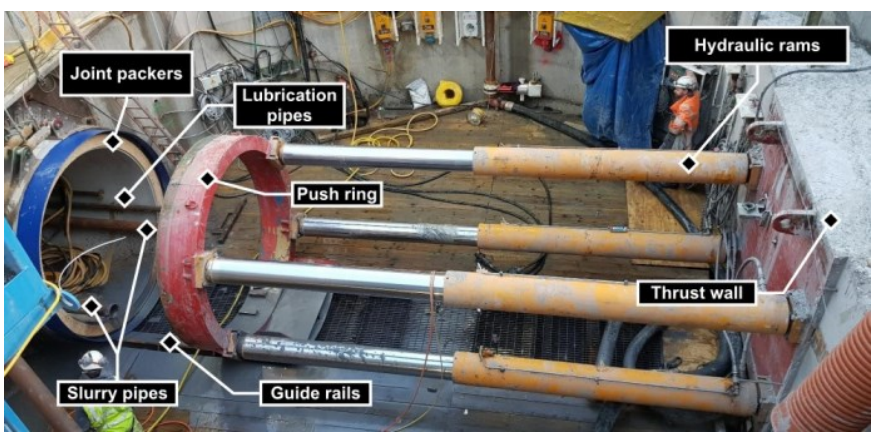

\section{Current design practice}

\subsection{Structural capacity of jacking pipes}

The design of steel bar reinforced concrete pipes is considered here as these are the pipes predominantly used by Ward and Burke Construction Ltd (WB) for their tunnelling activities, such as those at the pilot project. Commercial design of pipes to resist axial forces is governed predominantly by BS EN 640 and 641 (BSI, 1995a, 1995b), the British Tunnelling Society Specification (BTS and ICE, 2010), and the UK Pipe Jacking Association's guide to best practice (PJA, 1995). The latter adopts the 'linear stress approach' documented in the Concrete Pipe Association of Australasia (2013) for the calculation of the axial capacity of the pipe. In general, the design calculations are simplified closed-form expressions. A nonuniform distribution of force across the pipe joints, arising from deviation in pipe alignment, is the worst-case design scenario. For straight drives it is assumed that the contact stress in the packers between pipes varies linearly from zero at the pipe crown to a maximum stress $f$ at the invert. The maximum allowable force in the pipe, $P_{\max }$, is therefore determined as:

$P_{\text {max }}=0.5 A_{\mathrm{p}} f$

where $A_{\mathrm{p}}$ is the cross-sectional area of the packers between pipes and $f$ is determined from the concrete strength, $F_{\mathrm{ck}}$, factored by $\gamma$ as follows:

$f=F_{\mathrm{ck}} / \gamma$

Packers are typically a compressible material, such as medium density fibreboard (MDF), to enable efficient load transfer between pipes without a direct concrete-concrete connection. For curved drives, additional reductions are made to account for the increased angle at pipe joints, as this leads to smaller load transfer areas. Standard tables for the capacity of common pipe sizes are documented in PJA (1995) and CPAA (2013).

\subsection{Pipe-soil interface friction}

There is currently no universally accepted theory for the calculation of skin friction forces during a tunnel drive. Although a number of different theories have been proposed in the literature, these pertain to specific ground conditions. The 
French Society for Trenchless Technology (FSTT, 2006) presents a comparison between pipe-soil frictional stresses monitored from drives in various ground conditions to predictions determined using two different approaches: (i) Terzaghi's 'trap-door' model (Terzaghi, 1943) to calculate stresses around the pipe and (ii) frictional sliding of the pipe under its own weight only. Clearly these approaches represent the two extremes of tunnel stability: (i) fully-collapsed bore where full pipe-soil contact is achieved, and (ii) fully-stable bore where the only contact is due to the self-weight of the pipe. Aside from the normal stress distribution acting on the pipe, an accurate estimation of the friction factor, $\mu$, is another critical design element. For example, the use of lubricant in a drive has been reported to reduce the frictional stresses by between $45 \%$ and $90 \%$ (FSTT 2006).

\section{Development of an instrumented pipe section}

\subsection{Instrumentation}

A concrete test pipe was instrumented for measurements of (a) local normal and shear contact stresses, (b) pore water pressures, and (c) pipe wall strains during pipe-jacking. The external contact stresses were monitored using four three-axis load cells (rated $5 \mathrm{kN}$ for each axis). The four load cells were fitted within bespoke waterproof aluminium housings and installed flush with the exterior surface of the pipe at locations $N, W, S$ and $E$ as shown in Figure 4. A pressure transducer, fitted with a filter cap to maintain saturation, was installed beside each load cell to monitor the porewater pressure in the tunnel annulus. Glycerine was used to saturate the pressure transducer and an additional rubber membrane was placed around the sensor for protection and to prevent loss of saturation; the membrane was only removed immediately prior to pipe installation.

Figure 4. Schematic of sensor locations.

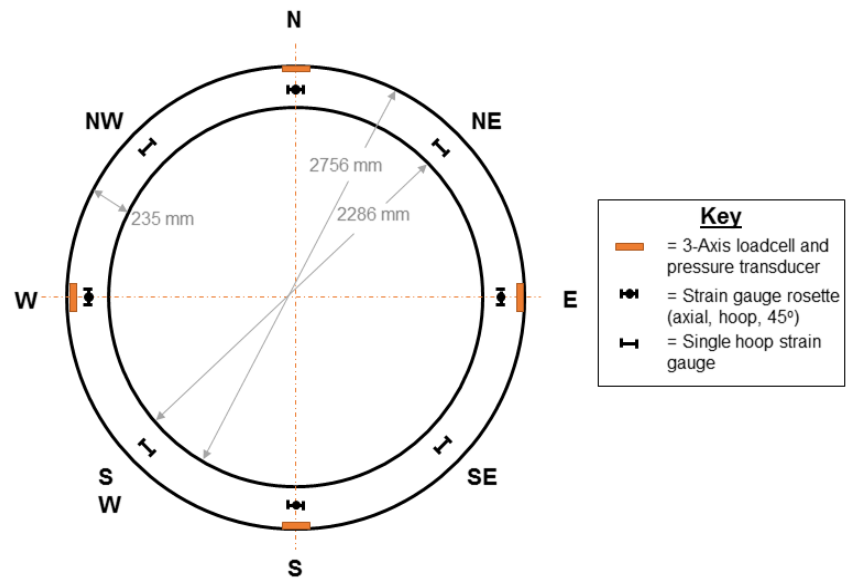

A total of 16 vibrating wire strain gauges were cast into the pipe wall, mounted to the outside reinforcement mat. This placed the sensors $60 \mathrm{~mm}$ from the exterior face of the pipe. At four locations ( $N, W, S, E$ - see Figure 5) the strain gauges were placed in rosette formation to measure axial, hoop and ' $45^{\circ}$, strains. An additional four strain gauges were deployed to measure hoop strains only, one each at locations $N W, S W, S E$ and $N E$. The strain gauges were logged at a rate of $1 / 60 \mathrm{~Hz}$ (maximum logging rate) whereas the pressure sensors and three-axis load cells were logged at $1 \mathrm{~Hz}$.

\subsection{Fabrication}

The pipe used for this research was 'wet cast'. The wet cast concrete mix is self-compacting, which due to significantly higher workability, meant vibration of the pipe was not required. The fabrication process for the instrumented pipe was as follows: (i) installation of outside mould, (ii) placement of prefabricated reinforcement cages, (iii) placement of sensors on outside reinforcement cage (see Figure 5), (iv) installation of inside mould, and (v) concrete casting. All sensor cables were routed to the interior face of the pipe and wrapped in foam so that they could be broken out after casting. The pipe was allowed to cure for 28 days before being transported to the launch location for the drive. Table 1 provides a summary of the key pipe parameters for the instrumented pipe section.

Table 1. Instrumented pipe parameter summary

\begin{tabular}{ll}
\hline Parameter (unit) & Value \\
\hline Length $(\mathrm{m})$ & 3 \\
Internal diameter $(\mathrm{mm})$ & 2286 \\
External diameter $(\mathrm{mm})$ & 2756 \\
Wall thickness $(\mathrm{mm})$ & 235 \\
Concrete strength, $F_{\text {ck }}(\mathrm{MPa})$ & 50 \\
Concrete Young's modulus $(\mathrm{GPa})$ & 37 \\
Pipe weight per $\mathrm{m}(\mathrm{kN} / \mathrm{m})$ & 46.5 \\
\hline
\end{tabular}

Figure 5. Pipe reinforcement and outside mould showing load cells, pressure transducers, and strain gauges fixed in place.

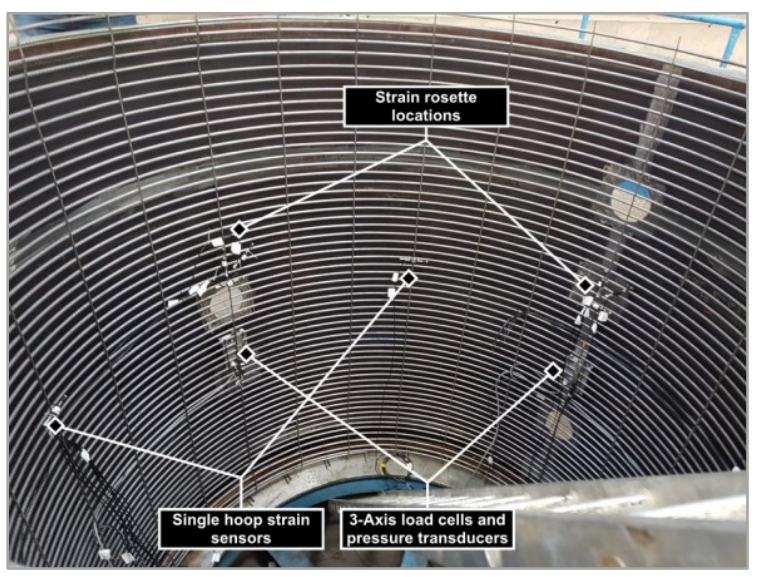

\section{Pilot monitoring project}

\subsection{Thirlmere link mains}

The instrumented pipe was trialled on a recent pilot project near Keswick, Cumbria, UK (see Figure 6). These construction works formed one of four pipe-jacked sections of a new $30 \mathrm{~km}$ pipeline from the Thirlmere reservoir to a new water treatment works near Cockermouth. It is part of the United Utilities West Cumbria Water Supplies Project. The majority of the pipeline 
is open cut with shallow cover. Inaccessible sections, such as those crossing beneath roads and rivers, are to be constructed using pipe-jacking. The pipeline will consist of twin gravityfed steel pipes for the majority of its length and intermittent ductile iron (pipe-jacked) sections. These pipes will be installed through the tunnels once complete along with ducts for additional communications and power cables. The contract for the construction of the project was awarded in April 2017, with the pipeline due for completion in October 2020 and the whole project being operational from March 2022.

Figure 6. Location of pilot project for this research (Keswick, UK).

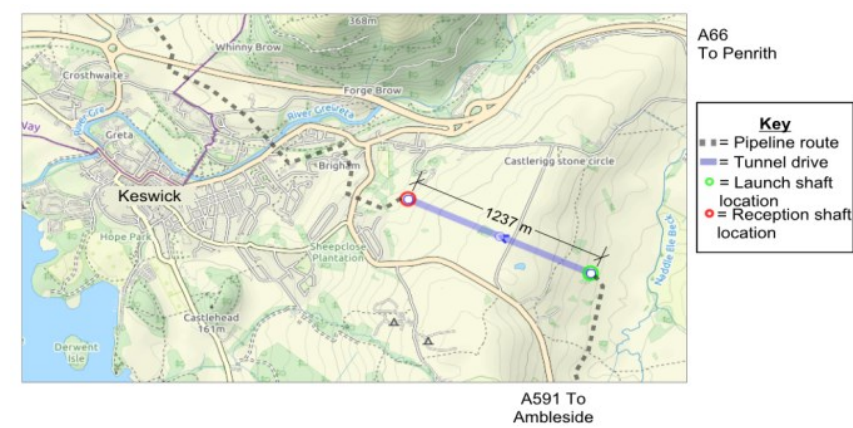

\subsection{Pilot tunnel drive}

The pilot drive for this research was a $2.76 \mathrm{~m}$ outside diameter, $1237 \mathrm{~m}$ long tunnel which is the longest pipe-jacked drive to be completed in the UK, to the authors' knowledge. The drive commenced on the $5^{\text {th }}$ of September 2018 and was completed on the $5^{\text {th }}$ of December 2018, as shown in Figure 7. Working hours for the first 35 days were 12-hour day shifts, five days per week, after which the working hours were $24 / 7$. The net advance rate was approximately $9 \mathrm{~m}$ per shift, equating to 12 $\mathrm{mm} / \mathrm{min}$ during working hours. When the TBM reached the reception shaft, the tunnel deviation was $<30 \mathrm{~mm}$ vertically and $<20 \mathrm{~mm}$ horizontally. The deviations did not exceed 110 $\mathrm{mm}$ at any point during the drive. The TBM used for the drive was a Herrenknecht (HK) AVN 2200. An additional trailing gantry was used to deliver $10 \mathrm{kV}$ high-voltage power to the machine rather than the standard $900 \mathrm{~V}$ supply. Due to the low abrasivity of the mudstone, only a single set of cutting disks in the TBM head were required for the drive.

Pipe-jacking was conducted in the downstream direction of the pipeline (from E-SE to W-NW) at a positive grade of $\sim 1 \%$ (to allow any water collecting in the invert to flow out during installation). Both shafts were constructed as temporary caissons. The launch shaft had an internal diameter of $11 \mathrm{~m}$ and wall thickness of $1 \mathrm{~m}$ whereas the reception shaft had an internal diameter of $8 \mathrm{~m}$ and wall thickness of $0.7 \mathrm{~m}$. Both shafts had plain concrete bases and minimal reinforcement within the walls (aside from the thrust wall). Once all works are completed the shafts will be backfilled and buried leaving no visible impact on the final landscape.
The annulus was lubricated using specially-designed 'lubrication pipes' comprising ports at three circumferential locations. These pipes were distributed along the length of the drive at spacings of $3 \mathrm{~m}$ (behind the TBM and either side of the IJS) and $15 \mathrm{~m}$ at all other locations. The lubrication was a mix of water, bentonite and polymer. The mixture was batched at ground level and delivered to the lubricant ports by three pressurised slurry lines within the tunnel, which can be seen in Figure 3. Each line provided a supply to a different section of the tunnel. These connected to valve control boxes in the pipes linked to the HK volume control management system which

Figure 7. Distance tunnelled - date relation for the pilot drive.

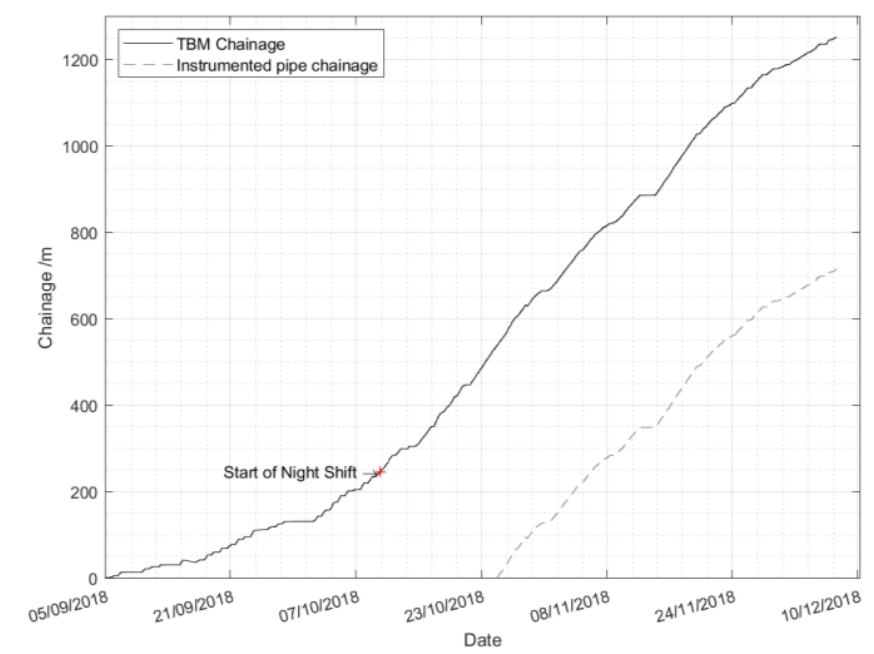

governed the valve timings and hence the pumped volume of bentonite.

\subsection{Ground conditions}

The drive predominantly passed through extremely weak to medium strong mudstone of low abrasivity and permeability. $1100 \mathrm{~m}$ of the drive was shown to be in these conditions by eleven boreholes along the alignment. The first $50 \mathrm{~m}$ and final $200 \mathrm{~m}$ of the drive was in superficial glacial till soils (sand and gravel lenses with cobbles and boulders in a matrix of clay) as the tunnel was closer to the ground surface. Key parameters of the ground conditions are shown in Table 2.

Table 2. Summary of ground conditions encountered for the majority of the drive.

\begin{tabular}{|c|c|}
\hline $\begin{array}{l}\text { Parameter } \\
\text { (unit) }\end{array}$ & $\begin{array}{l}\text { Design } \\
\text { Value }\end{array}$ \\
\hline Compressive strength ${ }^{\mathrm{a}, \mathrm{b}}(\mathrm{MPa})$ & $1-50$ \\
\hline Tensile strength ${ }^{\mathrm{b}}(\mathrm{MPa})$ & $<1$ \\
\hline Abrasivity $^{\mathrm{b}}$ & Low \\
\hline Permeability $^{\mathrm{c}}(\mathrm{m} / \mathrm{s})$ & $1 E^{-8}-1 E^{-5}$ \\
\hline Maximum cover $(\mathrm{m})$ & 57.8 \\
\hline Maximum pressure head $(\mathrm{m})$ & 25 \\
\hline
\end{tabular}




\subsection{Pipe installation}

Once the pipe was at the launch location, the data loggers and uninterruptable power supply (UPS) were mounted onto the pipe wall and the sensors cables were connected. The UPS was designed to provide continuous power to the data loggers during the pipe changes, and stoppages of up to three days, as power to the TBM was lost during these periods. Immediately prior to pipe installation, baseline readings ( 24 hours) were taken for all sensors with the pipe under no load. This was particularly important for the vibrating wire strain gauges as it was not possible to record the strains during curing. Once baseline readings had been taken the pipe was installed into the drive as pipe number 177, approximately $537 \mathrm{~m}$ behind the head of the TBM (see Figure 8).

Figure 8. Top: Pipe being lowered into position; Bottom: data loggers and UPS installed in tunnel pipe.
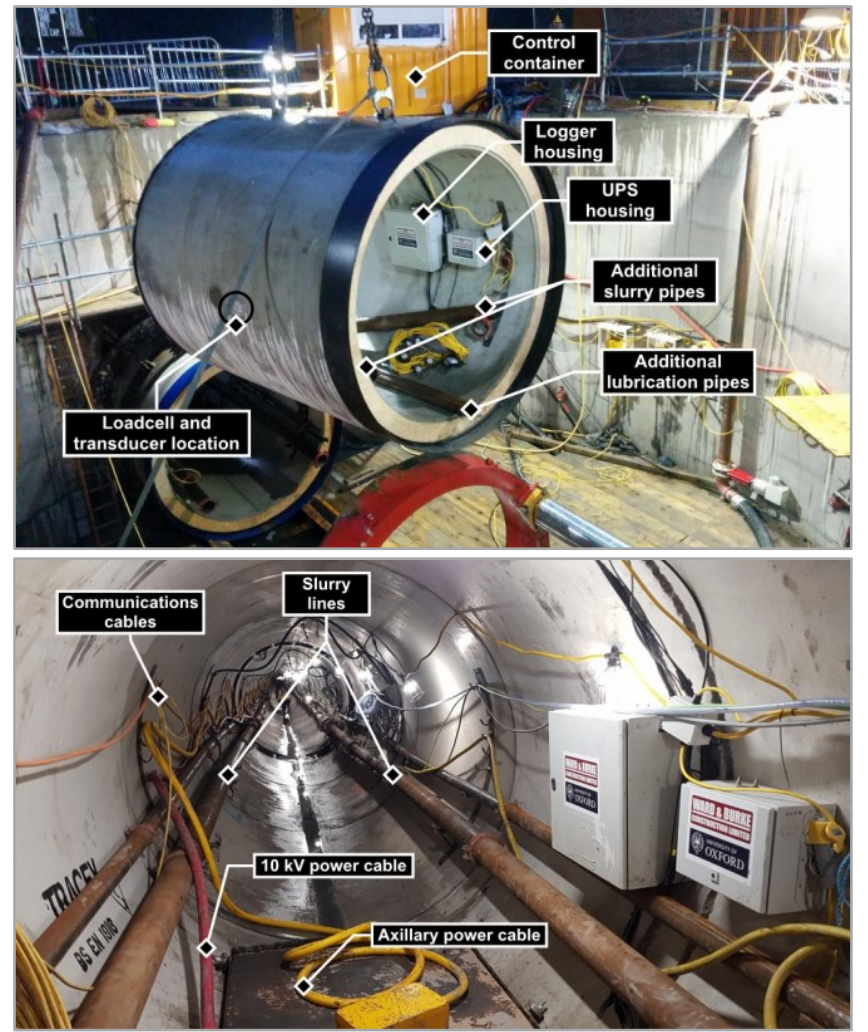

\section{Example results}

The total jacking forces $(P)$ and the TBM face resistance $(R-$ determined from the TBM steering cylinders), logged by the TBM during the drive are shown in Figure 9. Also superimposed on the plot are the axial forces in the instrumented pipe, deduced from the axial vibrating wire strain measurements as follows:

$F_{p}=\frac{\sum_{i=1}^{4} \varepsilon_{i}}{4} \times A_{w} \times E$

where $\varepsilon_{\mathrm{i}}$ is the axial strain of sensor $i, A_{\mathrm{w}}$ is the pipe wall area and $E$ is the pipe wall modulus (see Table 1). It can be seen that the total jacking forces peaked at $\sim 10,000 \mathrm{kN}$ at a chainage of $1150 \mathrm{~m}$. It can also be seen that the TBM face resistance was relatively constant during the drive, varying between $400 \mathrm{kN}$ and $1200 \mathrm{kN}$. The difference between the total jacking force and the face resistance was used to determine an average friction for the entire drive - this varied between $0.3 \mathrm{kPa}$ and 2 $\mathrm{kPa}$. These values are significantly lower than those previously quoted in the literature; e.g. Stein (2005) reported values of between $3 \mathrm{kPa}$ and $5 \mathrm{kPa}$. This shows that the lubrication regime was highly-effective during the drive. Furthermore, the forces on the instrumented pipe show good agreement with the total jacking forces initially, subsequently diverging due to the development of skin friction.

Figure 9. Jacking force, total steering cylinder force, average axial force on instrumented pipe

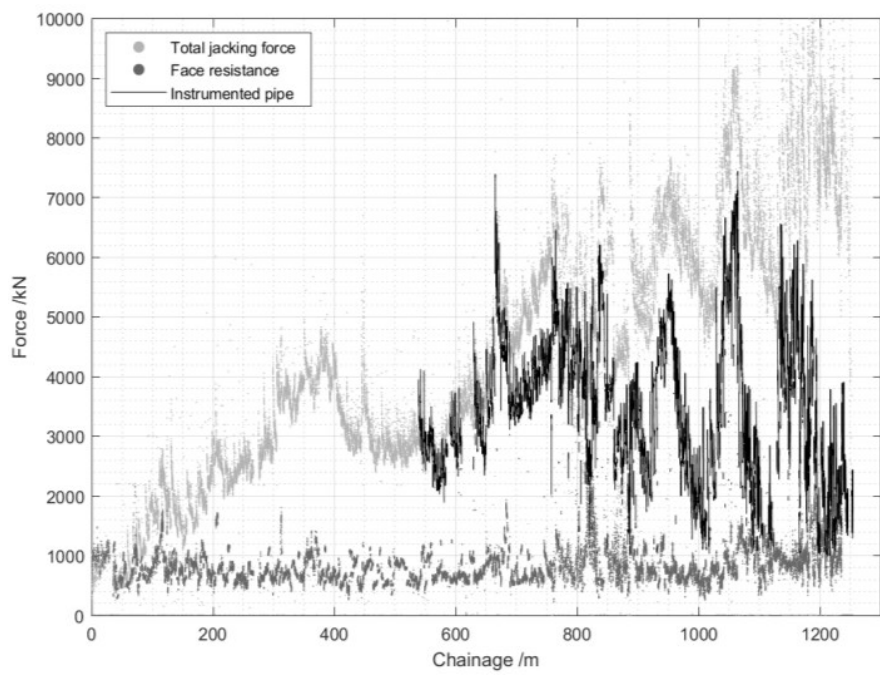

In Figure 10, the forces logged by the TBM (i.e. $P$ and $R$ ) for the initial $25 \mathrm{~m}$ of the drive are compared to verify their respective calibrations. If both measurements are correctly calibrated, it is expected that the measurements would be similar although the face resistance could be slightly lower due to friction of the guide rails. However, it can be seen that the face resistance is slightly larger than the total jacking force. There are two possible reasons for this: (i) one (or both) of the calibration factors is incorrect or (ii) the steering cylinders are supporting the head of TBM as it passed through the launch shaft wall thereby increasing the measured force. It is worth noting that these differences are small relative to the forces encountered during the drive $(3.6 \%$ of the maximum jacking force).

A similar comparison between the forces measured in the instrumented pipe and the total jacking force is presented in Figure 11. From the data it is clear that that the pipe is recording forces in excess of the jacking frame forces. The difference between the values ranged from $250 \mathrm{kN}$ to $330 \mathrm{kN}$ for the first $3 \mathrm{~m}$ of the drive (one pipe length). There are three potential causes of this discrepancy: (1) The jacking force measurements are under-recording the force values, this is supported by the comparison to the steering cylinder forces, (2) the elastic modulus $(E)$ used for the pipe was incorrect, and (3) the average of the four strain measurements $(\varepsilon)$ was not representative of the overall axial stress state within the pipe 
wall. The elastic modulus of the pipe was assumed constant for the duration of the drive. However, it is highly likely that the pipe was not fully-cured prior to installation. Application of a time dependant modulus related to the strength gain may provide a more accurate strain - stress correlation for the data

Figure 10. Comparison between total jacking force and face resistance for the initial $25 \mathrm{~m}$ of the pilot drive

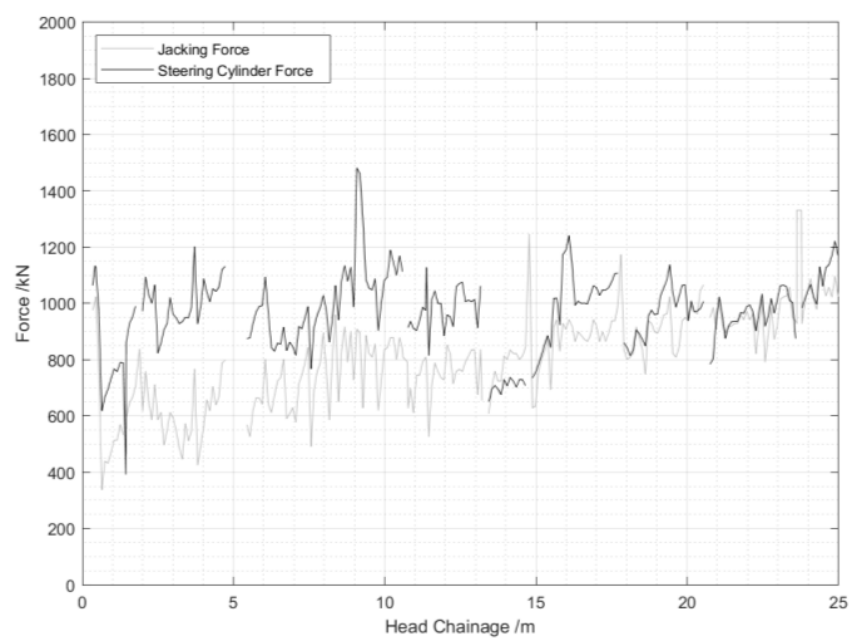

Figure 11. Comparison between total jacking force and pipe force for the initial $25 \mathrm{~m}$ of the pilot drive

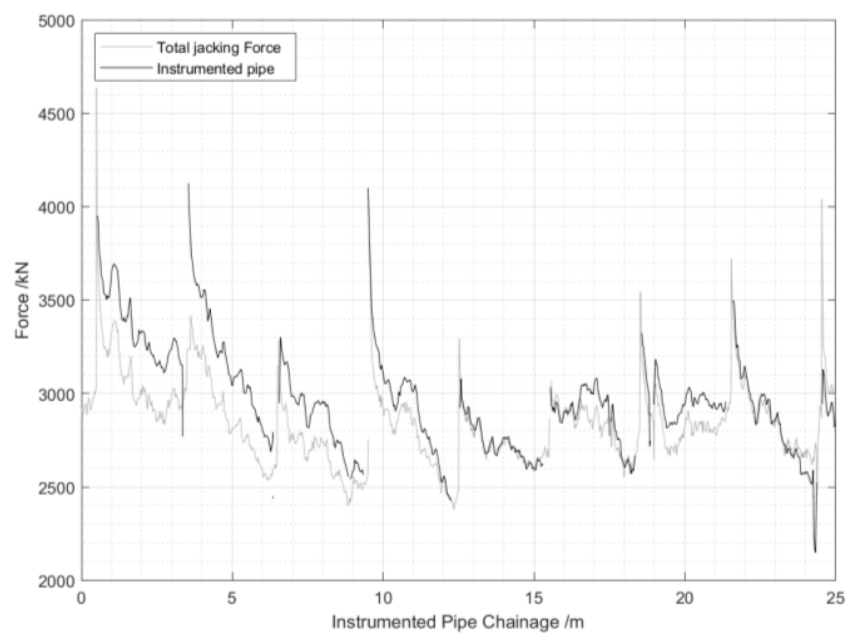

\section{Conclusions}

This paper has provided details of a tunnel drive in which an instrumented pipe section was installed for the purposes of monitoring the effects of pipe jacking on the jacking pipes and their interaction with the surrounding soil. Additional data from the tunnel boring machine control system have been analysed and have shown that the lubrication regime for the drive was very effect, with stresses lower than those quoted in the literature reviewed. It also identified that there are discrepancies between the different force outputs of the system which require further investigation.

\section{Acknowledgements}

The third author is supported by the Royal Academy of Engineering under the Research Fellowship scheme. The authors gratefully acknowledge the support of Ward and Burke Construction Ltd and Tracey Concrete for their support in casting, and installing the instrumented pipe section.

\section{References}

British Standards Institution (1995a) BS EN 640:1995, Reinforced concrete pressure pipes and distributed reinforcement concrete pressure pipes (non-cylinder type), including joints and fittings, BSI, London, UK

British Standards Institution (1995b) BS EN 641:1995, Reinforced concrete pressure pipes, cylinder type, including joints and fittings, BSI, London, UK

British Standards Institution (2012) BS EN ISO 22282-3:2012, Geotechnical investigation and testing. Geohydraulic testing. Water pressure tests in rock, BSI, London, UK

British Standards Institution (2018) BS EN ISO 14689:20181 , Geotechnical investigation and testing. Identification, description and classification of rock. Part 1: Identification and description, BSI, London, UK

The British Tunnelling Society and The Institution of Civil Engineers (2010) Specification for Tunnelling, Third Edition, Thomas Telford Ltd, London, UK

Concrete Pipe Association of Australasia (2013) CPAA Design Manual, Jacking Design Guidelines, https://tinyurl.com/ydfqq9zm (accessed 01/12/2018)

French Society for Trenchless Technology (2006) Microtunneling and Horizontal Drilling: Recommendations, John Wiley \& Sons, London.

International Society for Rock Mechanics and Rock Engineering (2007) The ISRM Suggested Methods for Rock Characterization, Testing and Monitoring 2007-2014, Springer, Basel, Switzerland

Japan Society of Trenchless Technology (1994) WorkingGroup No. 3, 1994. Microtunneling Jacking Force, Japan, p. 96.

Liu SY (2010), Slurry Dewatering in Pipe Jacking Industry, PhD Thesis, University of Leeds, Leeds, U.K.

Pellet-Beaucour AL and Kastner R (2002) Experimental and Analytical Study of Friction Forces during Microtunneling Operations, Tunnelling and Underground Space Technology 17(1): 83-97

Pipe Jacking Association (1995), Guide to best practice for the installation for pipe jacks and microtunnels, Pipe Jacking association, London

Stein, D. (2005). Trenchless Technology for Installation of Cables and Pipelines, Stein \& Partner, Bochum, Germany:

Terzaghi K (1943), Theoretical Soil Mechanics, John Wiley \& Sons, London 